\title{
Reviewer Acknowledgements for Global Journal of Health Science, Vol. 10, No. 2
}

Global Journal of Health Science wishes to acknowledge the following individuals for their assistance with peer review of manuscripts for this issue. Their help and contributions in maintaining the quality of the journal are greatly appreciated.

Global Journal of Health Science is recruiting reviewers for the journal. If you are interested in becoming a reviewer, we welcome you to join us. Please find the application form and details at http://recruitment.ccsenet.org and e-mail the completed application form to gjhs@ccsenet.org.

\section{Reviewers for Volume 10, Number 2}

Ama Pokuaa Fenny, University of Ghana, Ghana

Ayesha Johnson, University of South Florida, United States

Clauden Louis, University of Rochester Medical Center, United States

Delfina Gabriela Ramos, Polytechnic Institute of Cávado and Ave, Portugal

Dilek Pirim, Department of Molecular Biology and Genetics, Uludag University, Turkey

Evanthia Sakellari, Technological Educational Institute of Athens, Greece

Farahnaz Amini, UCSI University, Malaysia

Fengsong Gao, The University of Queensland, Australia

Fernanda Barbosa Lima-Christian, Federal University of Santa Catarina, Brazil

Francisco Rodenas Rigla, University of Valencia, Spain

Georgann Valerie Weissman, Capella University, United States

Hadii M Mamudu, East Tennessee State University, United States

Helen Lida Smits, Retired; serve as Faculty for the Institute of Healthcare Improvement in Boston, United States

Hilal Hamood Alrahbi, Diwan of Royal Court-Oman, Oman

Jaime Hinzpeter, Clinical Hospital University of Chile, Chile

Jingxian Cai, ICSA, ASA, ENAR, United States

Kartheek R Balapala, University Tunku Abdul Rahman, Malaysia

Loray Daws, British Columbia Masterson Institute, Canada

Marcel Wullschleger, Department of Physiology, University of Bern, Switzerland

Meng Zhao, Texas A\&M University at Corpus Christi, United States

Nant Thin Thin Hmwe, University of Newcastle, Australia

Pedram Iranmanesh, Dentist, Independent Researcher, Iran, Islamic Republic of

Pi-Ming Yeh, Missouri Western State University, United States

Pradnya V KAKODKAR, Dr. D Y Patil Patil Dental College and Hospital, India

Raildo da Silva Coqueiro, Universidade Estadual do Sudoeste da Bahia, Brazil

Robert Sloan, Kagoshima University Graduate School of Medical and Dental Sciences, Japan

Soon Soo Hoo, Royal North Shore Hospital. Sydney. Australia, Australia

Srikrishna Sulgodu Ramachandra, Public Health Foundation of India, India

Trisha Dunning, Deakin University and Barwon Health, Australia 